\title{
Article \\ Achieving High-Strength and Toughness in a Mg-Gd-Y Alloy Using Multidirectional Impact Forging
}

\author{
Songhe $\mathrm{Lu}^{1,2,+}$, Di Wu ${ }^{2,+}$, Ming Yan ${ }^{1}$ and Rongshi Chen ${ }^{2, *}$ \\ 1 Academy for Advanced Interdisciplinary Studies, Southern University of Science and Technology, \\ Shenzhen 518055, China; lush3@sustech.edu.cn (S.L.); yanm@sustech.edu.cn (M.Y.) \\ 2 Shi-Changxu Innovation Center for Advanced Materials, Institute of Metal Research, \\ Chinese Academy of Sciences, 72 Wenhua Road, Shenyang 110016, China; dwu@imr.ac.cn \\ * Correspondence: rschen@imr.ac.cn; Tel.: +86-24-2392-6646; Fax: +86-24-2389-4149 \\ + These authors contributed equally to this work.
}

check for updates

Citation: Lu, S.; Wu, D.; Yan, M.; Chen, R. Achieving High-Strength and Toughness in a Mg-Gd-Y Alloy Using Multidirectional Impact Forging. Materials 2022, 15, 1508. https://doi.org/10.3390/ ma15041508

Academic Editor: Frank Czerwinsk

Received: 10 January 2022

Accepted: 27 January 2022

Published: 17 February 2022

Publisher's Note: MDPI stays neutral with regard to jurisdictional claims in published maps and institutional affiliations.

Copyright: (C) 2022 by the authors. Licensee MDPI, Basel, Switzerland. This article is an open access article distributed under the terms and conditions of the Creative Commons Attribution (CC BY) license (https:// creativecommons.org/licenses/by/ $4.0 /)$

\begin{abstract}
High strength and toughness are achieved in the Mg-4.96Gd-2.44Y-0.43Zr alloy by multidirectional impact forging (MDIF). The forged sample has a fine-grained microstructure with an average grain size of $\sim 5.7 \mu \mathrm{m}$ and a weak non-basal texture, and it was characterized by an optical microscope $(\mathrm{OM})$, scanning electron microscope (SEM), and electron back-scattering diffraction (EBSD). Tensile results exhibit the tensile yield strength (TYS) and static toughness (ST) of as-homogenized alloy dramatically increased after forging and aging, i.e., the TYS increased from $135_{-5}^{+4} \mathrm{MPa}$ to $337_{-2}^{+2} \mathrm{MPa}$, and the ST enhanced from $22.0_{-0.5}^{+0.3} \mathrm{MJ} / \mathrm{m}^{3}$ to $50.4_{-5.4}^{+5.3} \mathrm{MJ} / \mathrm{m}^{3}$. Specifically, the forged $\mathrm{Mg}-\mathrm{Gd}-\mathrm{Y}-\mathrm{Zr}$ alloy owns higher TYS than that of commercial rolled WE54 (Mg-5.25Y-3.5Nd-0.5Zr) and WE43 (Mg-4.0Y-3.0Nd-0.5Zr) alloys.
\end{abstract}

Keywords: grain refinement; high strength and toughness; $\{10-12\}$ twin; Mg-Gd-Y alloy; multidirectional impact forging

\section{Introduction}

$\mathrm{Mg}$ and its alloys, as structural materials for automobile and electronics industries, can meet the demands of weight reduction and increasing vehicle efficiency [1,2]. Unluckily, they exhibited relatively low yield strength and toughness in comparison to their competitors $\mathrm{Al}$ and $\mathrm{Ti}$ alloys [3]. To improve their mechanical property, some strengthening mechanisms (including solution and precipitation strengthening) have been applied to block the dislocation glide and achieve the enhancement of the yield strength but the degradation of the toughness [4-6]. In contrast, fine-grained strengthening has been considered as a promising way for synchronously enhancing the strength and toughness of $\mathrm{Mg}$ alloys. Furthermore, the corresponding strengthening effect in $\mathrm{Mg}$ alloys is more remarkable due to their larger slope coefficient of the Hall-Petch relationship ( $\sim 3$ times larger than that of aluminum alloy) [7].

Fine-grained AZ31 [8], AZ61 [9], AZ80 alloys [10] have been produced mainly by conventional deformation routes including rolling, extrusion, and forging, and the corresponding recrystallization predominantly proceeded from prior grain boundaries and then consumed the entire deformed microstructure easily. However, the above recrystallization mechanism was seriously suppressed in some RE (rare earth)-containing $\mathrm{Mg}$ alloys [11,12]. For instance, the microstructure of Mg-8.2Gd-3.8Y-1.0Zn-0.4Zr (wt.\%) alloy rolled at $400{ }^{\circ} \mathrm{C}$ consisted of a large volume of residual coarse grains and some recrystallization distributed at the prior grain boundary [11]. A similar recrystallization behavior also was witnessed in the microstructure of extruded Mg-7.5Gd-2.5Y-3.5Zn-0.9Ca- $0.4 \mathrm{Zr}$ (wt.\%) alloy [12]. This should be originated from the strong solute drag or pinning effect of RE-rich precipitates on dislocation glide and rearrangement, especially for those grain boundaries having intensive segregation of solute atoms. In other words, these grain 
boundaries have already lost the function of recrystallization nucleation. To produce the fine-grained RE-containing Mg alloys, it is necessary to offer appropriate nucleation sites in the grain interior for recrystallization.

Mechanical twinning can serve as an important deformation mechanism in the plastic deformation of the Mg-RE alloys [13]. The corresponding twin boundaries generated in the grain interior may be the preliminary candidate for recrystallization nucleation [14]. For common $\{10-12\}$ extension, $\{10-11\}$ contraction and $\{10-11\}-\{10-12\}$ double twins, the latter two is difficulty to be utilized well due to their larger critical resolved shear stress (CRSS $\geq 70 \mathrm{MPa})[15,16]$ and crack tendency [17]. In contrast, the former $\{10-12\}$ twin with relatively low CRSS ( 10 MPa) is easy to be activated and accommodates the extension strain along the c-axis [18]. Hence, the $\{10-12\}$ twin boundary may take the place of the initial grain boundary and act as preference nucleation sites for recrystallization of the RE-containing Mg alloys.

Recently, $\{10-12\}$ twin activated by multidirectional impact forging (MDIF) has been successfully applied to activate $\{10-12\}$ twin and produce fine-grained Mg-6.68Gd-5.9Y$0.48 \mathrm{Zr}$ (wt.\%) alloy $[19,20]$. In contrast to recrystallization assisted by dislocation rearrangement, $\{10-12\}$ twin induced recrystallization has many advantages as follows. Firstly, mutual intersections of two-dimensional \{10-12\} twin boundaries are easy to form threedimensional recrystallization nuclei. Secondly, the fresh twin boundary can store enough strain energy to promote recrystallization nucleation through the repeated twin-dislocation interaction during the dynamic forging procedure [19]. Finally, recrystallization grains initiated from $\{10-12\}$ twin boundary are more effective in achieving microstructure refinement of the Mg-Gd-Y alloy alloys.

In the present work, a high-strength and toughness Mg-Gd-Y alloy has been developed by MDIF using $\{10-12\}$ twin and correlated recrystallization. Then, the contribution of $\{10-12\}$ twins to microstructure refinement and property enhancement of Mg-Gd-Y-Zr alloy have been discussed in detail.

\section{Materials and Methods}

The material used in the present study was GW52 alloy ingot (Mg-4.96Gd-2.44Y-0.43Zr, mass fraction, \%). The as-cast GW52 alloy ingot was homogenized at $480^{\circ} \mathrm{C}$ for $8 \mathrm{~h}$ with subsequent cooling in air, and then it was cut into some cubic sample with dimensions of $70 \times 70 \times 70 \mathrm{~mm}^{3}$. These cubic samples were first heated to $480{ }^{\circ} \mathrm{C}$ in an electric resistance furnace and kept for $60 \mathrm{~min}$. In addition, the heating rate is $15^{\circ} \mathrm{C} / \mathrm{min}$. Then, the multidirectional impact forging (MDIF) was carried out using an industrial air pneumatic hammer machine (Shandong Chu Hang Heavy Industry Machinery Co., Ltd., Weifang, China) with a load gravity of $250 \mathrm{Kg}$. A pass strain $\sim 0.05$ was applied and the average strain rate was around $20 \mathrm{~s}^{-1}$. The procedure during the MDIF was shown in Figure 1a. One of the cubic samples was forged to 200 passes with an intermediate annealing treatment for $\sim 10 \mathrm{~min}$ at $480^{\circ} \mathrm{C}$, and it was termed as MDIF100+100 sample (symbol + means an intermediate annealing treatment for $\sim 10 \mathrm{~min}$ after the first 100 forging passes). The entire forging and annealing process finished in $15 \mathrm{~min}$. After carefully checking, the MDIF100+100 sample was free from any surface defects, as shown in its macro-morphology image Figure $1 b$.

To examine the microstructure and mechanical property, the MDIF100+100 sample was sectioned in the center along the last forging direction (LFD), as shown in Figure 1c. The corresponding specimens for optical microscopy (OM) (Carl Zeiss AG, Oberkochen, Germany), scanning electron microscopy (SEM) (Carl Zeiss AG, Oberkochen, Germany), and tension test was machined from the center part, as indicated by red arrows in Figure 1c. The electron back-scattering diffraction (EBSD) observations were carried out using a TESCAN-MIRA3 SEM (TESCAN, Brno, Czech Republic) operating at $20 \mathrm{kV}$ and applying a corresponding probe current of $60 \mathrm{nA}$. Orientation imaging microscopy was measured at a step size of $1 \mu \mathrm{m}$ and the acquired EBSD data was analyzed using the software of Aztec Crystal 4.3 (Oxford Instruments, Abingdon, UK). Texture analysis was conducted using the Schultz 
reflection method through X-ray diffraction and calculated pole figures were obtained using the DIFFRAC plus TEXEVAI software (Bruker, Karlsruhe, Germany). The tensile specimens in dog bone shape were cut from the central part of the forged cubic sample with a gauge length of $20 \mathrm{~mm}$, a width of $3 \mathrm{~mm}$, and a thickness of $2.5 \mathrm{~mm}$. The compression specimens in-cylinder were also machined from the same position with a height of $15 \mathrm{~mm}$ and a diameter of $10 \mathrm{~mm}$, as shown in Figure 1c.

(a)
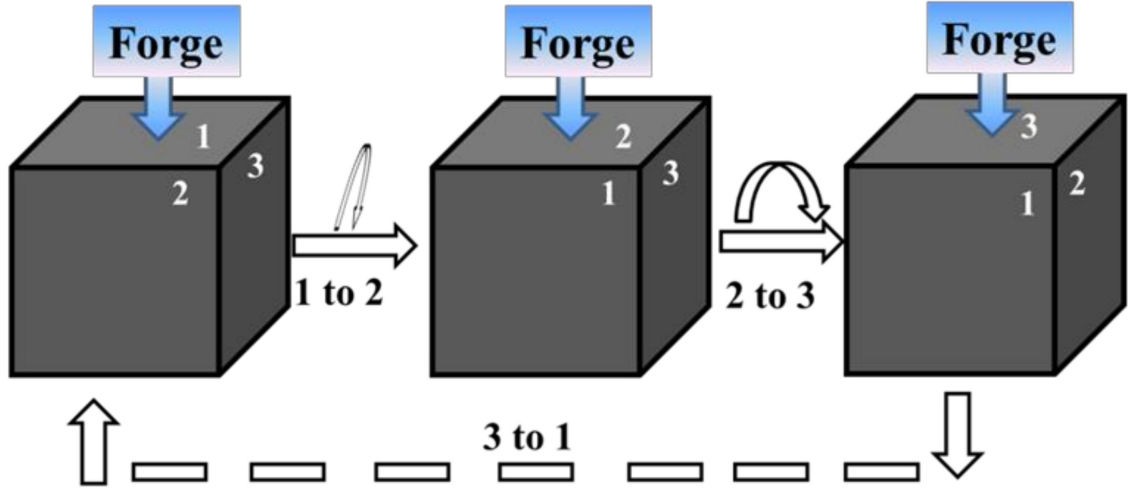

3 to 1

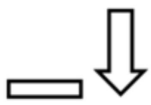

(b)
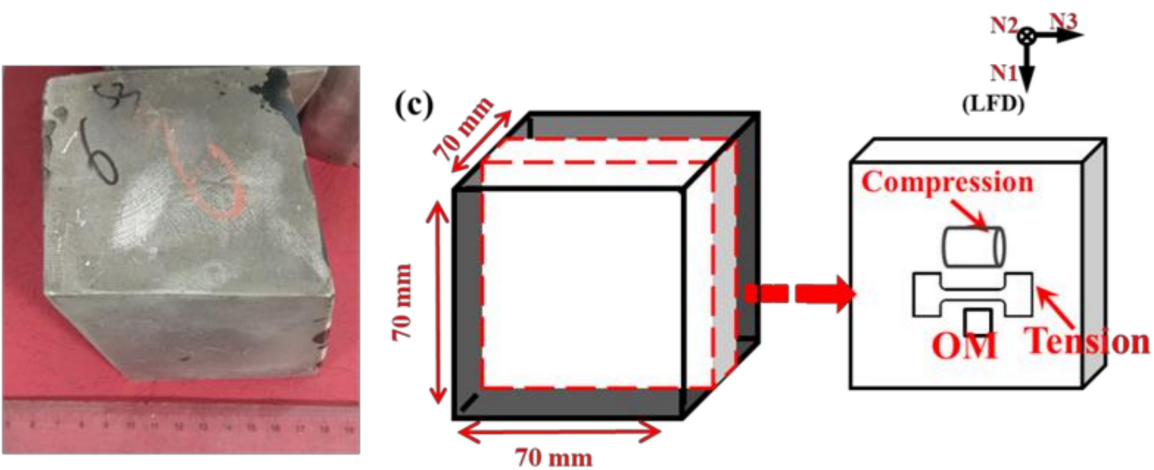

Figure 1. (a) Schematic illustrations of the MDIF process, (b) macro-morphology of MDIF100+100 sample and (c) schematic diagram describing the orientations of the tensile specimens and the compression specimens relative to the forged billet.

\section{Results}

\subsection{Initial State of the Alloy}

Figure 2 displays the EBSD results of the microstructure of GW52 alloy after homogenization at $480{ }^{\circ} \mathrm{C}$ for $8 \mathrm{~h}$. The inverse pole figure exhibit many equiaxed grains with random orientation in the microstructure of as-homogenized alloy, as shown in Figure 2a. This is consistent with the $\{0001\}$ pole figure in Figure $2 \mathrm{~d}$. The corresponding grain boundary map consists of an as-homogenized microstructure with some second phases in Figure $2 \mathrm{~b}$. Most of these phases in Mg-Gd-Y were identified as cuboid-shaped phases in previous reference [20], which were detected as $\mathrm{YH}_{2}$ through a combined analysis of secondary ion mass spectrometry (SIMS) and X-ray tomography (XRT). Many black dots in Figure $2 \mathrm{~b}$ may be the corrosion products of the second phase produced by electrolytic polishing. The average grain size of $47 \mu \mathrm{m}$ has been evaluated through the grain size distribution map in Figure 2c.

\subsection{Microstructure and Mechanical Property of MDIF100+100 Sample}

Figure 3 gives OM and corresponding $\{0001\}$ macro texture of the MDIF100+100 sample of GW52 alloy. It can be observed a deformed microstructure in low magnification of OM in Figure 3a. High-magnification observation captured some coarse grains $\sim 10 \mu \mathrm{m}$ and a large number of small grains $\sim 1 \mu \mathrm{m}$, as indicated by their respective arrows in Figure $3 \mathrm{~b}$. Besides, the corresponding $\{0001\}$ macrotexture in Figure $3 c$ illustrates a non-basal texture with many peaks (the intensity $\leq 3.79$ multiples of random (mrd)). 

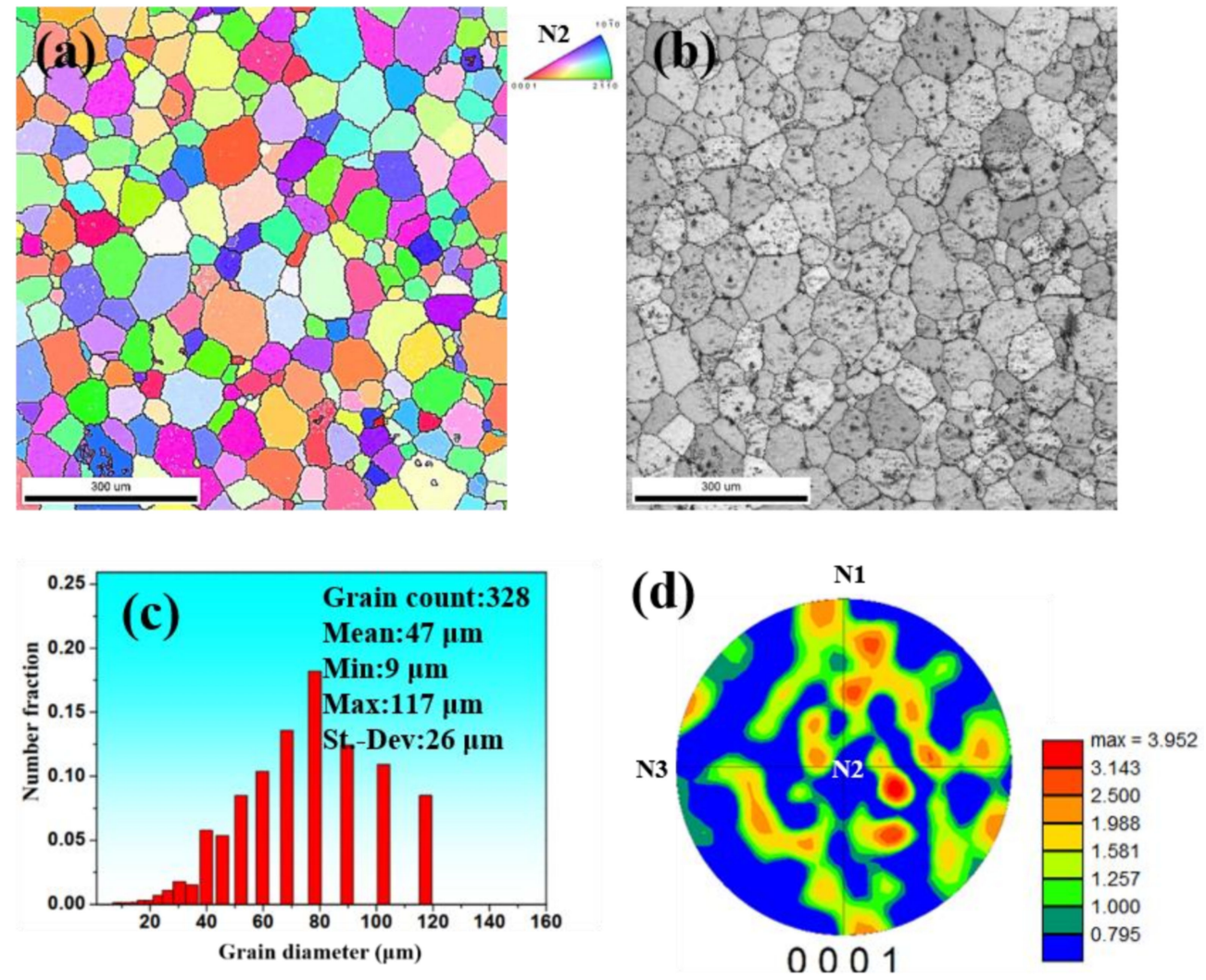

Figure 2. (a) Inverse pole figure, (b) grain boundary image, (c) grain size distribution map, and (d) $\{0001\}$ pole figure of as-homogenized GW52 alloy.
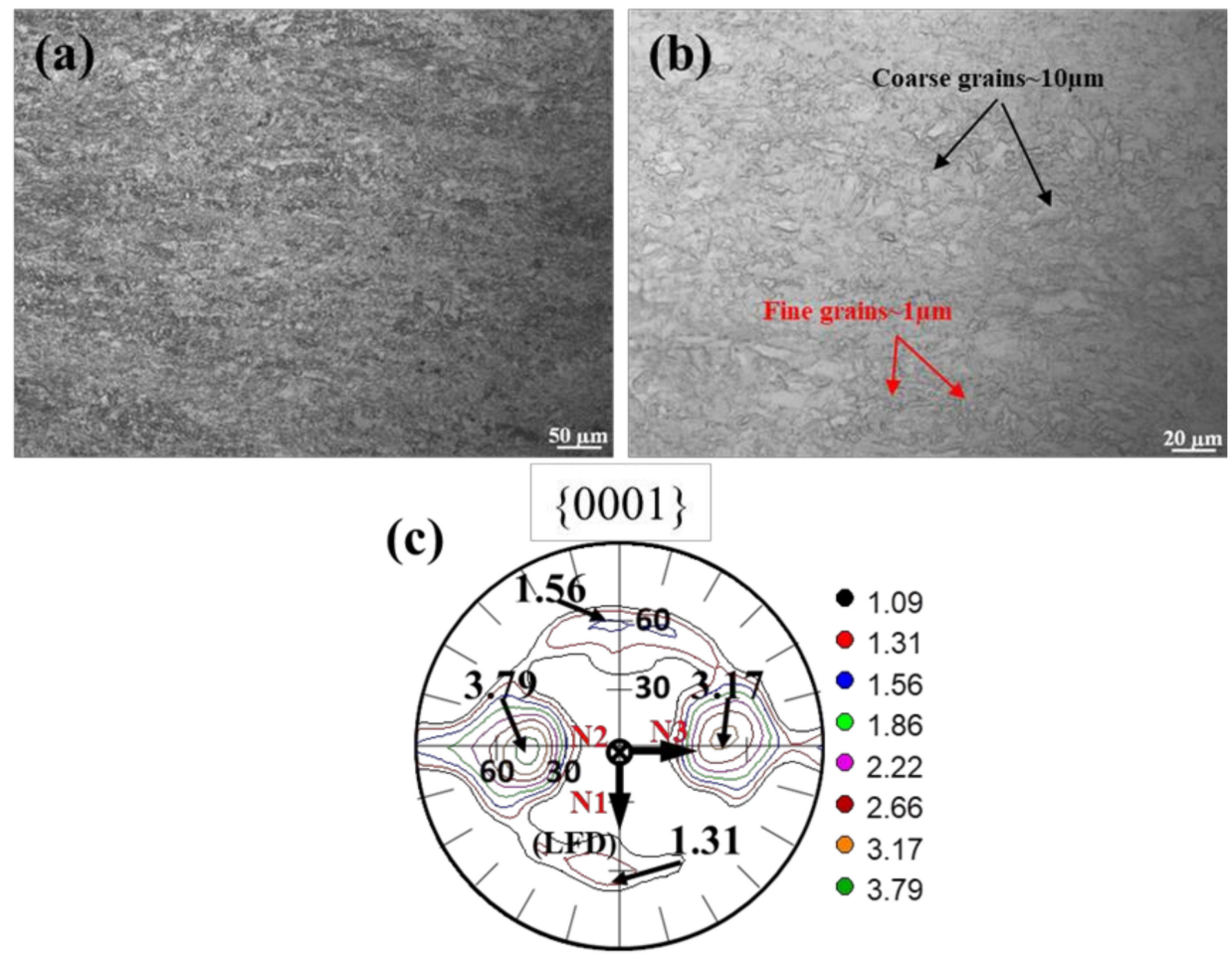

Figure 3. (a) Low magnification and (b) high magnification of $\mathrm{OM}$ as well as corresponding (c) \{0001\} macrotexture of MDIF100+100 sample of GW52 Mg alloy at the center location $(\sim 35 \mathrm{~mm})$. 
The corresponding EBSD results of the final forging microstructure were shown in Figure $4 \mathrm{a}-\mathrm{e}$. We noted that flourishing twins were activated in the microstructure, especially in several coarse regions, as shown in Figure $4 \mathrm{a}, \mathrm{b}$. The special boundaries results in Figure $4 \mathrm{~b}$ demonstrate that the fraction of $\{10-12\}$ twin boundary $\left(<11-20>86^{\circ}\right)$ is $11.8 \%$, while the fraction of $\{10-11\}$ twin boundary $\left(<11-20>56^{\circ}\right)$ and $\{10-11\}-\{10-12\}$ twin boundary $<11-20>38^{\circ}$ are $0.23 \%$ and $0.40 \%$, respectively. This is consistent with the larger fraction of $\{10-12\}$ twin boundaries in the misorientation angle of grain boundaries in Figure 4e. In addition, low angle grain boundaries (LAGBs) also have a larger number fraction in this forged alloy in Figure 4e. As shown in the grain size distribution histogram of Figure $4 \mathrm{~d}$, the final average grain diameter of the GW52 alloy was decreased to $\sim 5.7 \mu \mathrm{m}$. Moreover, the fraction of the fine grins $(\leq 20 \mu \mathrm{m})$ in the final forging microstructure was about $87 \%$. In particular, the $\{0001\}$ pole figure in Figure $4 \mathrm{~d}$ exhibited the fine-grained alloy possess a non-basal texture (the intensity $\leq 4.13 \mathrm{mrd}$ ). Specifically, MDIF with intermediate annealing treatment is an effective route to produce fine-grained $\mathrm{Mg}$ - $\mathrm{RE}$ alloys with nonbasal texture.
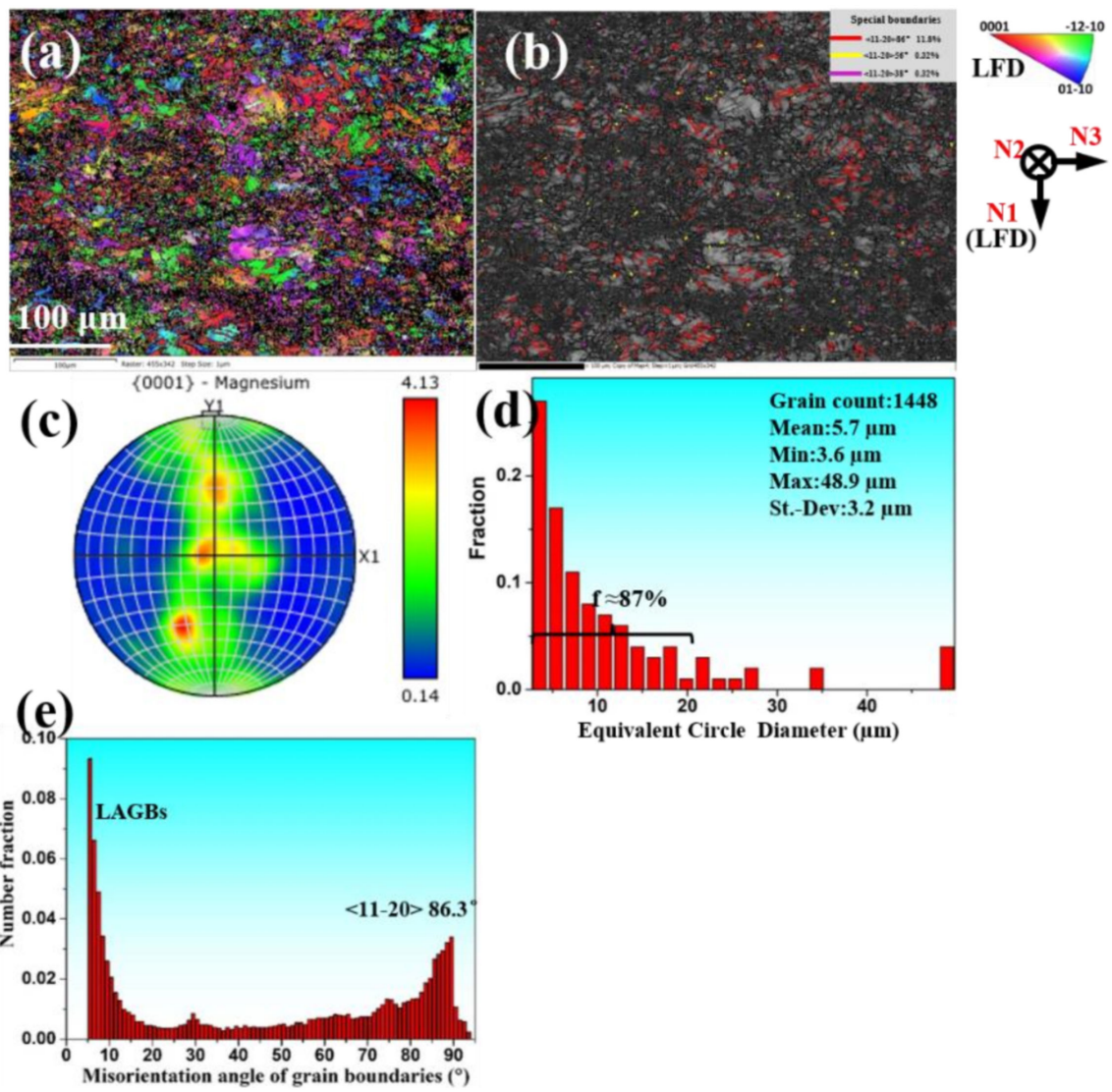

Figure 4. (a) Inverse pole figure map, (b) band contrast map, (c) $\{0001\}$ pole figure, (d) grain size distribution histogram, and (e) misorientation angle of grain boundaries of MDIF100+100 sample of GW52 alloy at the center location $(\sim 35 \mathrm{~mm})$.

Figure 5 presents room temperature tensile engineering stress-strain curves of ashomogenized, forged, and aged GW52 alloy. The tension results were listed in Table 1 . The static toughness (ST) usually can be measured by the true stress-strain curve, which can be obtained from their respective engineering stress-strain curve through data processing. The true stress can be calculated by this equation: $S=\sigma^{*}(1+\varepsilon)$. Then, $S T$ was measured by the equation $\mathrm{ST}=\int_{0}^{\varepsilon_{k}} S d \varepsilon$ [21,22]. In addition, $\mathrm{S}$ means true stress and $\varepsilon \mathrm{k}$ is the value of true strain after the sample fractured. The corresponding results have been illustrated in Table 1. 

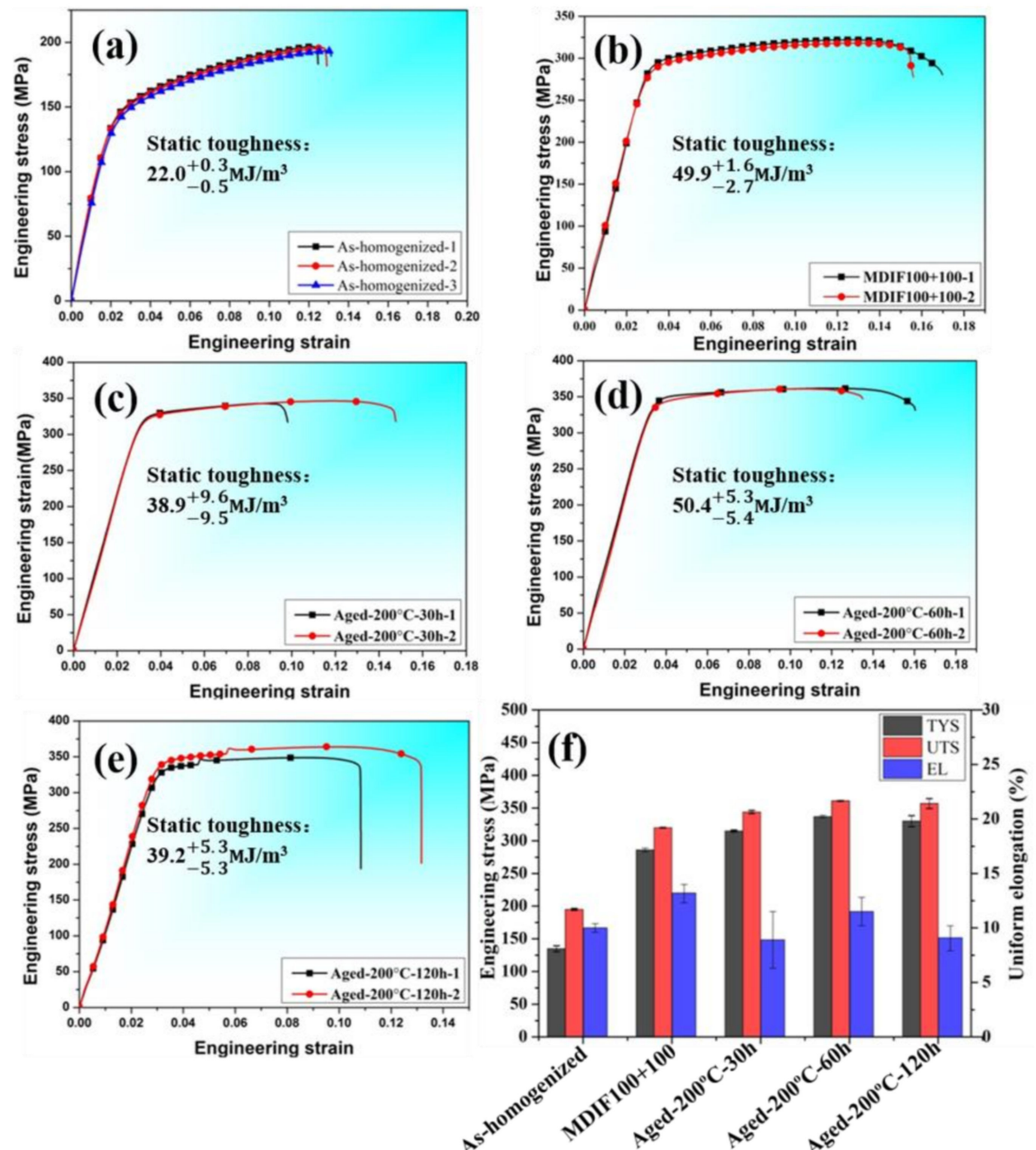

Figure 5. Room temperature tensile engineering stress-strain curves (a-e) and corresponding properties (f) of as-homogenized, MDIF100+100, and aged MDIF100+100 samples of GW52 alloy with their respective static toughness: (a) as-homogenized alloy, (b) MDIF100+100, (c) aged at $200{ }^{\circ} \mathrm{C}$ for $30 \mathrm{~h}$, (d) aged at $200{ }^{\circ} \mathrm{C}$ for $60 \mathrm{~h}$, (e) aged at $200{ }^{\circ} \mathrm{C}$ for $120 \mathrm{~h}$.

Table 1. Room temperature tensile and compressive properties of GW52 alloy.

\begin{tabular}{cccccc}
\hline & $\begin{array}{c}\text { TYS } \\
(\mathbf{M P a})\end{array}$ & UT/CS(MPa) & EL (\%) & ST(MJ/m ${ }^{\mathbf{3}}$ ) & CYS/TYS \\
\hline As-homogenized-1 & 139 & 197 & 9.6 & 21.5 & \\
As-homogenized-2 & 137 & 196 & 10.0 & 22.2 & \\
As-homogenized-3 & 130 & 194 & 10.4 & 22.3 & \\
MDIF100+100-ten-1 & 289 & 321 & 14.0 & 52.5 & \\
MDIF100+100-ten-2 & 283 & 319 & 12.3 & 47.2 & $\approx 1$ \\
MDIF100+100-com-1 & 294 & 465 & 13.0 & - & \\
MDIF100+100-com-2 & 310 & 469 & 11.0 & - & \\
Aged-200 ${ }^{\circ} \mathrm{C}-30 \mathrm{~h}-1$ & 316 & 341 & 6.2 & 29.3 & \\
Aged-200 ${ }^{\circ} \mathrm{C}-30 \mathrm{~h}-2$ & 313 & 346 & 11.5 & 48.4 & \\
Aged-200 ${ }^{\circ} \mathrm{C}-60 \mathrm{~h}-1$ & 339 & 361 & 12.8 & 55.7 & \\
Aged-200 ${ }^{\circ} \mathrm{C}-60 \mathrm{~h}-2$ & 335 & 360 & 10.2 & 45.0 & \\
Aged-200 ${ }^{\circ} \mathrm{C}-120 \mathrm{~h}-1$ & 322 & 364 & 7.9 & 33.9 & \\
Aged-200 ${ }^{\circ} \mathrm{C}-120 \mathrm{~h}-2$ & 339 & 349 & 10.2 & 44.5 &
\end{tabular}

TYS, tension yield strength; UTS, ultimate tensile strength; EL, uniform elongation; CYS, compression yield strength; ST, static toughness. 
It can be observed in Figure 5a that the tensile yield strength (TYS), uniform elongation

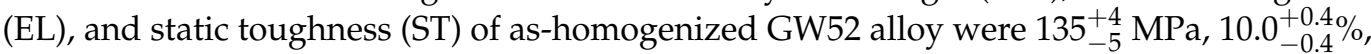
and $22.0_{-0.5}^{+0.3} \mathrm{MJ} / \mathrm{m}^{3}$, respectively. After the MDIF of 100+100 passes, the strength, ductility, and toughness of GW52 alloy were synchronously enhanced in Figure 5b, i.e., the TYS, EL, and ST dramatically increased to $286_{-3}^{+3} \mathrm{MPa}, 13.2_{-0.9}^{+0.8} \%$, and $49.9_{-1.7}^{+1.6} \mathrm{MJ} / \mathrm{m}^{3}$, respectively. It has been reported that aging treatment at $200{ }^{\circ} \mathrm{C}$ was usually applied to $\mathrm{Mg}$-RE alloys to further enhance their strength [23-25]. In the present work, some tensile specimens of GW52 alloy were aged at $200{ }^{\circ} \mathrm{C}$ for different times $(30 \mathrm{~h}, 60 \mathrm{~h}$, and $120 \mathrm{~h})$. The strength and toughness often were synchronously enhanced in Figure $5 c-e$, i.e., foraged alloy at $200{ }^{\circ} \mathrm{C}$ for $60 \mathrm{~h}$, the TYS, UTS, and ST sharply increased to $337_{-2}^{+2} \mathrm{MPa}, 361_{-1}^{+0} \mathrm{MPa}$, and $40.1_{-5.3}^{+4.7} \mathrm{MJ} / \mathrm{m}^{3}$, respectively.

Figure 6a shows the comparison of mechanical properties in numerous forged Mg-Al$\mathrm{Zn}$ alloys and Mg-Gd-Y-based alloys [10,26-39]. The forged Mg-Al-Zn-based alloys were generally located at the bottom corner [10,27-33], while the MDIF100+100 sample of GW52 alloy was located at the center part exhibiting a higher TYS. Furthermore, the forged GW52 alloy exhibited excellent strength-ductility balance in comparison to the forged Mg-Gd-Ybased alloys [34-39]. Specifically, the TYS and EL of the forged GW52 alloy are larger than that of rolling or extrusion of commercial WE54 and WE43 alloys produced by Magnesium Elektron Ltd. (Magnesium Elektron, Manchester, UK), in Figures S1 and S2 (Supplementary Materials), as shown in Figure 6a. Above all, the forged GW52 alloy demonstrates tensioncompression yield symmetry along N3 forging direction (the ratio of CYS/TYS was $\approx 1.0$ ) in Figure $6 \mathrm{~b}$, which means that we obtained yield isotropy Mg-Gd-Y alloy with high strength and toughness. This tension-compression yield symmetry character is rarely examined in the rolling sheet or extrusion of high-strength Mg-RE alloy [40]. It can be concluded that a fine-grained GW52 alloy has been produced by MDIF using \{10-12\} twin and correlated recrystallization with the excellent mechanical property. Thus, the contribution of $\{10-12\}$ twins to microstructure refinement and property enhancement of GW52 alloy should be discussed in detail.

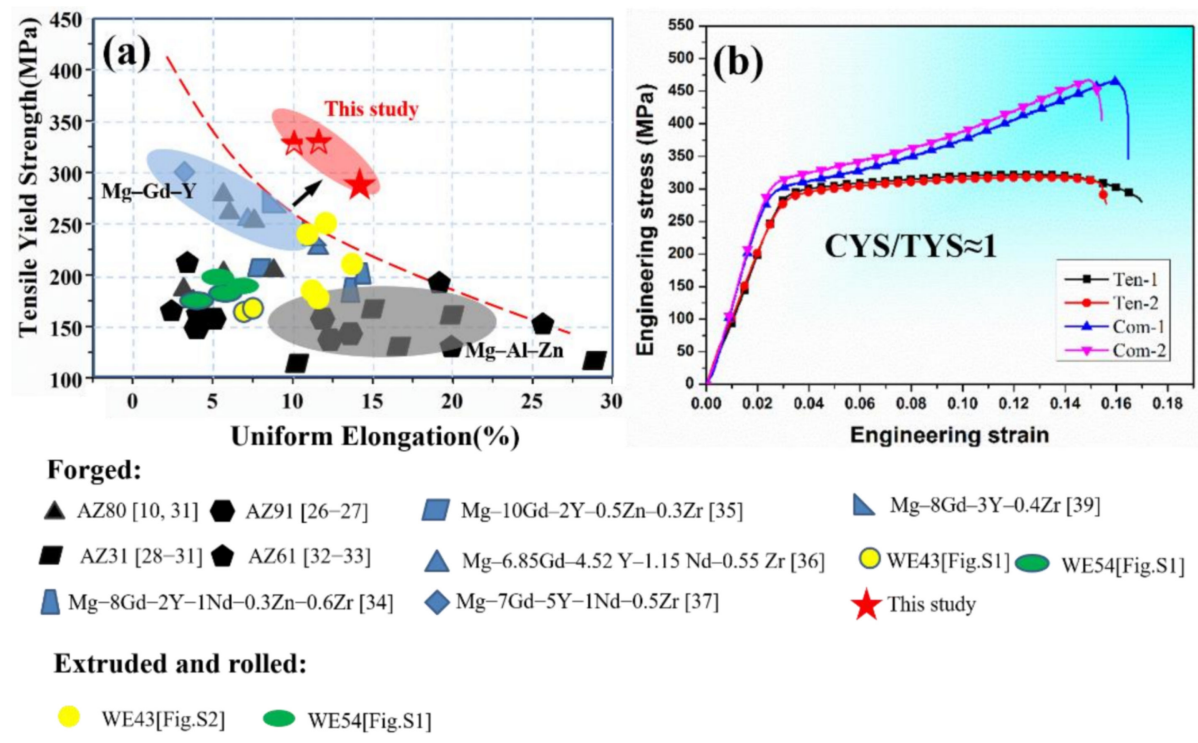

Figure 6. (a) Relationships between tensile yield strength and elongation of forged Mg-Al-Zn based and $\mathrm{Mg}$-Gd-Y-based alloys as well as (b) tension-compression engineering stress-strain curves of MDIF100+100 sample of GW52 alloy.

\section{Discussion}

\subsection{Contribution of $\{10-12\}$ Twins to Microstructure Refinement}

It has been reported that $\{10-12\}$ twins usually exerted different functions at dynamic forging and annealing treatment in our previous works [19,20]. At the dynamic forging 
process, MDIF with a high strain rate and small strain is favorable for twin nucleation but twin growth [20]. Additionally, the three directional loadings are beneficial for activating $\{10-12\}$ twins in $79.8 \%$ of grains in the microstructure of the as-homogenized Mg-Gd-Y alloy [20]. Meanwhile, these twins can divide their parent grains, interact repeatedly with various dislocations, and then store enough strain energy, eventually promoting the nucleation of DRX [20]. With the progress of intermediate annealing, above $\{10-12\}$ twins with high strain energy can act as preference nucleation sites for static recrystallization, thereby making for a preliminary microstructure refinement [19]. Next, this fine-grained microstructure was ready for the next generation of $\{10-12\}$ twin. At the sequent dynamic forging passes, the fresh $\{10-12\}$ twins can be activated again and subdivide those new grains achieving further microstructure refinement. It can be concluded that MDIF with intermediate annealing can effectively refine the microstructure of $\mathrm{Mg}-\mathrm{Gd}-\mathrm{Y}$ alloy through $\{10-12\}$ twin and correlated recrystallization.

The above microstructural results can be evidenced by the fine-grained microstructure with extensive $\{10-12\}$ twins, as shown in inverse pole figure map and band contrast map of Figure $4 \mathrm{a}, \mathrm{b}$. The distribution histogram of grain size had been examined in Figure $4 \mathrm{~d}$, and the average grain size of the GW52 alloy sharply decreased from $\sim 47 \mu \mathrm{m}$ of as-homogenized alloy to $\sim 5.7 \mu \mathrm{m}$. We noted that the fraction of the fine grins $(\leq 20 \mu \mathrm{m})$ dramatically increased to $87 \%$. This means that MDIF with intermediate annealing had produced a fine-grained Mg-Gd-Y alloy using $\{10-12\}$ twin and correlated recrystallization.

\subsection{High Strength and Toughness GW52 Alloy}

After the MDIF of 100+100 forging passes, the TYS of GW52 alloy increased from $135_{-5}^{+4} \mathrm{MPa}$ to $286_{-3}^{+3} \mathrm{MPa}$ and the ST also increased from $22.0_{-0.5}^{+0.3} \mathrm{MJ} / \mathrm{m}^{3}$, to $49.9_{-1.7}^{+1.6} \mathrm{MJ} / \mathrm{m}^{3}$. As a result, the MDIF realized $151 \mathrm{MPa}$ increment $(112 \%)$ for TYS and $22.0 \mathrm{MJ} / \mathrm{m}^{3}$ increment $(117 \%)$ for ST. Meanwhile, the average grain size of the alloy sharply decreased from $\sim 47 \mu \mathrm{m}$ of as-homogenized alloy to $\sim 5.7 \mu \mathrm{m}$. The strengthening and toughening mechanisms will be discussed in detail as follows.

For the strengthening mechanism, fine-grained strengthening and twin strengthening should be focused on in the present work. Based on the stress intensity factor, k, obtained using the Hall-Petch relationship of GW53 alloy [41], the increment of TYS induced by grain refinement was calculated at about $112 \mathrm{MPa}$. It can be concluded that fine-grained strengthening determines the increment of TYS of GW52 alloy. Besides, flourishing twins were activated in the microstructure, especially in several coarse regions, as shown in Figure $4 a, b$. The special boundaries results in Figure $4 b$ demonstrate that the fraction of $\{10-12\}$ twin boundary $\left(<11-20>86^{\circ}\right)$ is $11.8 \%$, while the fraction of $\{10-11\}$ twin boundary $\left(<11-20>56^{\circ}\right)$ and $\{10-11\}-\{10-12\}$ twin boundary $<11-20>38^{\circ}$ are $0.23 \%$ and $0.40 \%$, respectively. As a result, the crack tendency of $\{10-11\}$ compression and $\{10-11\}-\{10-12\}$ double twin can almost be neglected $[42,43]$. As a result, a large number of $\{10-12\}$ twin boundaries as typical two-dimensional planar defects can interact with basal slip and even impede the dislocation movement [44]. Therefore, fine grain and twin strengthening play a key role in the high-strength GW52 alloy.

For the toughening mechanism, intergranular deformation including grain sliding and grain rotation usually serves as the dominating deformation mechanism in the plastic deformation of fine-grained GW52 alloy $(\sim 5.7 \mu \mathrm{m})$. Meanwhile, deformation mechanisms will have a significant transition from primary basal slip to some potential non-basal slip in fine-grained alloy with the grain size $<10 \mu \mathrm{m}$ [45]. In addition, a large volume of $\{10-12\}$ twin boundaries as typical two-dimensional planar defects exerted an obstructing effect on dislocation glide and allow the penetration of dislocation under the high stressconcentration [44]. On the other hand, the fine-grained GW52 alloy with a random texture tends to activate various dislocation slip, which was evidenced by their higher average SF (Schmid factor) value $(\geq 0.28)$ for various slip systems (basal slip $<a>$ : $\{0001\}<11-20>$, prismatic slip $<$ a $>$ : $\{1-100\}<11-20>$, pyramidal slip $<a>$ : $\{1-101\}<11-20>$, and pyramidal slip $<c+a>$ : $\{11-22\}<11-2-3>$ ), as shown in Figure 7 . In other words, various slips will 
be activated and steadily accommodate the tensile strain according to the Von Mises criteria [46]. All of these changes can ensure a uniform deformation and suppress the premature failure of $\mathrm{Mg}$ alloy. Hence, the fine-grained microstructure obtained by MDIF plays an important role in this high strength and toughness Mg-Gd-Y alloy.

(a)
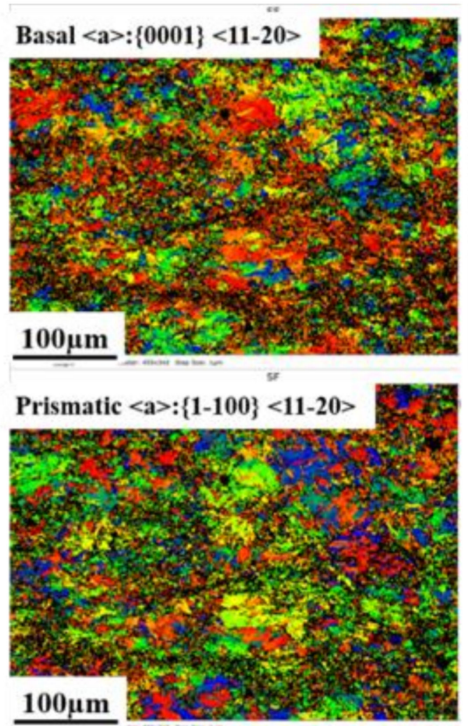

(b)

(c)

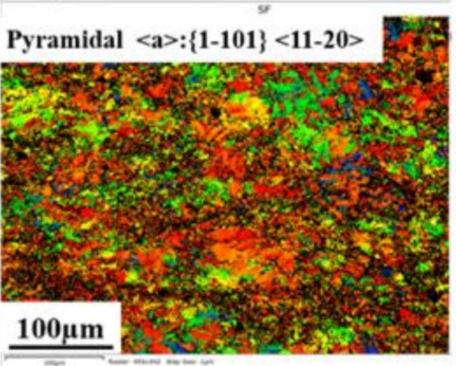

$\underline{100 \mu \mathrm{m}}$

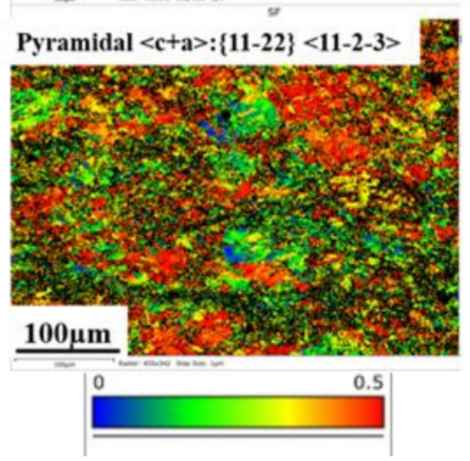

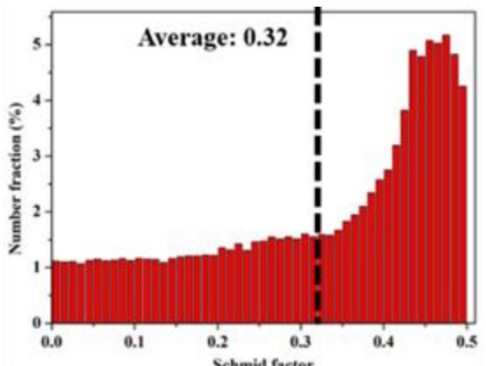
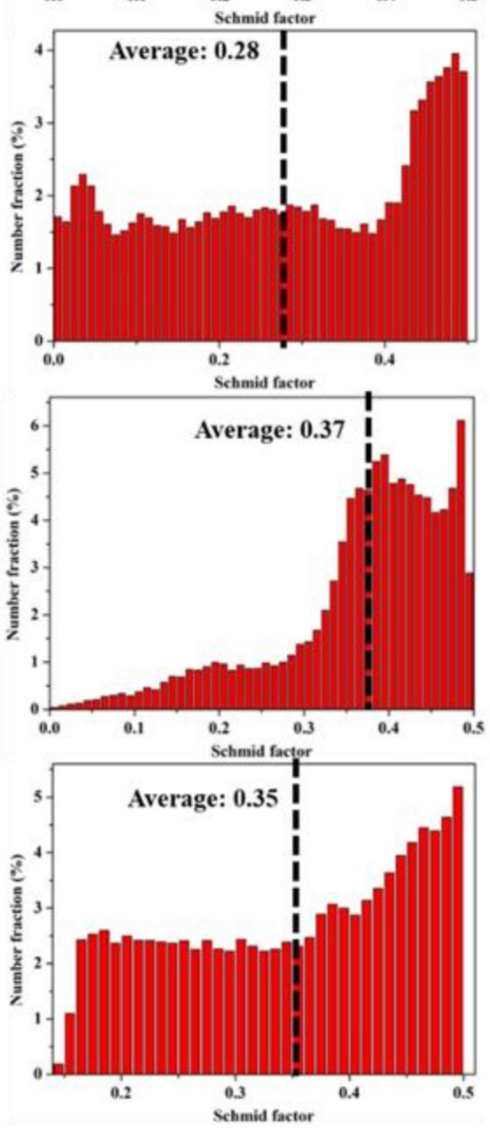

Figure 7. SF maps and corresponding distribution histograms for various slip systems of MDIF100+100 sample of GW52 alloy: (a) basal slip <a>:\{0001\}<11-20>, (b) prismatic slip <a : $\{1-100\}$ $<11-20>$, (c) pyramidal slip $<a>:\{1-101\}<11-20>$, (d) pyramidal slip $<\mathrm{c}+\mathrm{a}\rangle:\{11-22\}<11-2-3\rangle$.

\section{Conclusions}

Multidirectional impact forging has been applied to grain refinement and property enhancement of Mg-Gd-Y alloy in the present work. The main results can be summarized as follows:

(1) Multidirectional impact forging has been proved to be an efficient methodology in grain refinement and property improvement of Mg-Gd-Y alloy. After the MDIF of 100+100 forging passes, the TYS of GW52 alloy increased from $135_{-5}^{+4} \mathrm{MPa}$ to $286_{-3}^{+3} \mathrm{MPa}$ and the ST also increased from $22.0_{-0.5}^{+0.3} \mathrm{MJ} / \mathrm{m}^{3}$, to $49.9_{-1.7}^{+1.6} \mathrm{MJ} / \mathrm{m}^{3}$. As 
a result, the MDIF realized $151 \mathrm{MPa}$ increment $(112 \%)$ for TYS and $22.0 \mathrm{MJ} / \mathrm{m}^{3}$ increment $(117 \%)$ for ST simultaneously.

(2) The MDIF100+100 sample of GW52 alloy has a relatively fine-grained microstructure $\sim 5.7 \mu \mathrm{m}$, exhibiting a random texture. Furthermore, high TYS of $337_{-2}^{+2} \mathrm{MPa}$, EL of $11.5_{-1.3}^{+1.3} \%$, and ST of $50.4_{-5.4}^{+5.3} \mathrm{MJ} / \mathrm{m}^{3}$ were gained in the GW52 alloy developed by MDIF and aging treatment.

(3) The forged GW52 alloy exhibits yield isotropy (the ratio of compression yield strength/ tensile yield strength along the forging direction is $\approx 1.0$ ). Compared with forged $\mathrm{Mg}$ $\mathrm{Al}-\mathrm{Zn}$ and Mg-Gd-Y based alloys, the forged GW52 alloy exhibited excellent strengthductility balance resulting from the combined effect of fine-grained strengthening, twin strengthening, and its non-basal texture.

Supplementary Materials: The following are available online at https:/ /www.mdpi.com/article/10

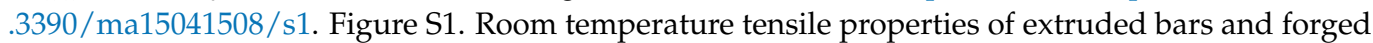
billets of commercial WE43 and WE54 alloys produced by Elektron Ltd. (London, UK); Figure S2. Room temperature tensile properties of rolled plate and extruded bar of commercial WE43 alloys produced by Elektron Ltd (London, UK).

Author Contributions: Investigation, writing-review \& editing, S.L.; supervision, review \& editing, D.W. and R.C.; review \& editing, M.Y. All authors have read and agreed to the published version of the manuscript.

Funding: This work was funded by the National Natural Science Foundation of China (NSFC) through Projects No. 52171055, the National Science and Technology Major Project of China through Project No. 2017ZX04014001, and the Natural Science Foundation of Liaoning province through Projects No. 20180550799.

Institutional Review Board Statement: Not applicable.

Informed Consent Statement: Not applicable.

Data Availability Statement: The data presented in this study are available upon request from the corresponding author. The data are not publicly available due to the requirements of related projects.

Conflicts of Interest: The authors declare they have no known competing financial interests or personal relationships that could have influenced the work reported in this paper.

\section{References}

1. Zhang, K.; Zheng, J.-H.; Huang, Y.; Pruncu, C.; Jiang, J. Evolution of twinning and shear bands in magnesium alloys during rolling at room and cryogenic temperature. Mater. Des. 2020, 193, 108793. [CrossRef]

2. Pan, H.; Kang, R.; Li, J.; Xie, H.; Zeng, Z.; Huang, Q.; Yang, C.; Ren, Y.; Qin, G. Mechanistic investigation of a low-alloy Mg-Ca-based extrusion alloy with high strength-ductility synergy. Acta Mater. 2020, 186, 278-290. [CrossRef]

3. Springer, H.; Baron, C.; Szczepaniak, A.; Uhlenwinkel, V.; Raabe, D. Stiff, light, strong and ductile: Nano-structured High Modulus Steel. Sci. Rep. 2017, 7, 2757. [CrossRef]

4. Zheng, R.; Du, J.-P.; Gao, S.; Somekawa, H.; Ogata, S.; Tsuji, N. Transition of dominant deformation mode in bulk polycrystalline pure Mg by ultra-grain refinement down to sub-micrometer. Acta Mater. 2020, 198, 35-46. [CrossRef]

5. Zhang, B.; Wang, Y.; Geng, L.; Lu, C. Effects of calcium on texture and mechanical properties of hot-extruded Mg-Zn-Ca alloys. Mater. Sci. Eng. A 2012, 539, 56-60. [CrossRef]

6. Hagihara, K.; Li, Z.; Yamasaki, M.; Kawamura, Y.; Nakano, T. Strengthening mechanisms acting in extruded Mg-based long-period stacking ordered (LPSO)-phase alloys. Acta Mater. 2019, 163, 226-239. [CrossRef]

7. Chen, Z.H. Wrought Magnesiun; Chemical Industry Press: Beijing, China, 2005; p. 5.

8. Jiang, M.; Xu, C.; Yan, H.; Fan, G.; Nakata, T.; Lao, C.; Chen, R.; Kamado, S.; Han, E.; Lu, B. Unveiling the formation of basal texture variations based on twinning and dynamic recrystallization in AZ31 magnesium alloy during extrusion. Acta Mater. 2018, 157, 53-71. [CrossRef]

9. Huang, X.; Suzuki, K.; Chino, Y.; Mabuchi, M. Texture and stretch formability of AZ61 and AM60 magnesium alloy sheets pro-cessed by high-temperature rolling. J. Alloys Compd. 2015, 632, 94-102. [CrossRef]

10. Zhou, X.; Zhang, J.; Chen, X.; Zhang, X.; Li, M. Fabrication of high-strength AZ80 alloys via multidirectional forging in air with no need of ageing treatment. J. Alloys Compd. 2019, 787, 551-559. [CrossRef] 
11. Xu, C.; Zheng, M.Y.; Wu, K.; Wang, E.D.; Fan, G.H.; Xu, S.W.; Kamado, S.; Liu, X.D.; Wang, G.J.; Lv, X.Y.; et al. Effect of final rolling reduction on the microstructure and mechanical properties of Mg-Gd-Y-Zn-Zr alloy sheets. Mater. Sci. Eng. A 2013, 559, 232-240. [CrossRef]

12. Xie, Z.Y.; Tian, Y.; Li, Q.; Zhou, J.C.; Meng, Y. Effect of extrusion parameters on mi-crostructure and mechanical properties of Mg-7.5Gd-2.5Y-3.5Zn-0.9Ca-0.4Zr (wt\%) alloy. Mater. Sci. Eng. A 2017, 685, 159-167.

13. Lu, S.; Wu, D.; Chen, R.; Han, E.-H. The influence of temperature on twinning behavior of a Mg-Gd-Y alloy during hot compression. Mater. Sci. Eng. A 2018, 735, 173-181. [CrossRef]

14. Lu, S.; Wu, D.; Chen, R.; Han, E.-H. The effect of twinning on dynamic recrystallization behavior of Mg-Gd-Y alloy during hot compression. J. Alloys Compd. 2019, 803, 277-290. [CrossRef]

15. Zhu, S.; Yan, H.; Liao, X.; Moody, S.; Sha, G.; Wu, Y.; Ringer, S. Mechanisms for enhanced plasticity in magnesium alloys. Acta Mater. 2015, 82, 344-355. [CrossRef]

16. Basu, I.; Al-Samman, T. Twin recrystallization mechanisms in magnesium-rare earth alloys. Acta Mater. 2015, 96, 111-132. [CrossRef]

17. Barnett, M. Twinning and the ductility of magnesium alloys: Part II. "Contraction" twins. Mater. Sci. Eng. A 2007, 464, 8-16. [CrossRef]

18. Chapuis, A.; Driver, J.H. Temperature dependency of slip and twinning in plane strain compressed magnesium single crystals Acta Mater. 2011, 59, 1986-1994. [CrossRef]

19. Lu, S.H.; Wu, D.; Chen, R.S.; Han, E.H. Microstructure and texture optimization by static recrystallization originating from $\{10-12\}$ extension twins in a Mg-Gd-Y alloy. J. Mater. Sci. Technol. 2020, 59, 44-60. [CrossRef]

20. Lu, S.H.; Wu, D.; Chen, R.S.; Han, E.H. Reasonable utilization of $\{10-12\}$ twin for optimizing microstructure and improving mechanical property in a Mg-Gd-Y alloy. Mater. Des. 2020, 191, 108600-108621. [CrossRef]

21. Yao, T.Z.; Xu, T.H.; Wang, D.H. Effect of yield ratio rising on use security of pipeline steels. Mater. Mech. Eng. 2012, 36, 62-68.

22. Cai, W.; Morovat, M.A.; Engelhardt, M.D. True stress-strain curves for ASTM A992 steel for fracture simulation at elevated temperatures. J. Constr. Steel Res. 2017, 139, 272-279. [CrossRef]

23. Xue, Z.Y.; Ren, Y.J.; Luo, W.B.; Ren, Y.; Xu, P.; Xu, C. Microstructure and mechanical properties of Mg-Gd-Y-Zn-Zr alloy sheets processed by combined processes of extrusion, hot rolling and ageing. Mater. Sci. Eng. A 2013, 559, 844-851. [CrossRef]

24. Li, J.L.; Zhang, N.; Wang, X.X.; Wu, D.; Chen, R.S. Effect of Solution Treatment on the Microstructure and Mechanical Properties of Sand-Cast Mg-9Gd-4Y-0.5Zr Alloy. Acta Metall. Sin. Engl. Lett. 2017, 31, 189-198. [CrossRef]

25. Hou, X.; Cao, Z.; Wang, L.; Xu, S.; Kamado, S.; Wang, L. Microstructure and mechanical properties of extruded Mg-8Gd-2Y-1Nd0.3Zn-0.6Zr alloy. Mater. Sci. Eng. A 2011, 528, 7805-7810. [CrossRef]

26. Nie, K.; Wang, X.; Deng, K.; Xu, F.; Wu, K.; Zheng, M. Microstructures and mechanical properties of AZ91 magnesium alloy processed by multidirectional forging under decreasing temperature conditions. J. Alloys Compd. 2014, 617, 979-987. [CrossRef]

27. Nie, K.; Deng, K.; Wang, X.; Xu, F.; Wu, K.; Zheng, M. Multidirectional forging of AZ91 magnesium alloy and its effects on microstructures and mechanical properties. Mater. Sci. Eng. A 2015, 624, 157-168. [CrossRef]

28. Guo, W.; Wang, Q.; Ye, B.; Zhou, H. Enhanced microstructure homogeneity and mechanical properties of AZ31-Si composite by cyclic closed-die forging. J. Alloys Compd. 2013, 552, 409-417. [CrossRef]

29. Liu, Z.Y.; Jiang, X.Q.; Mu, F.; Li, H.D. Development progress of plastic working for AZ31 magnesium alloy. Light Met. 2008, 12, 59-63. [CrossRef]

30. Chen, C.; Wang, R.; Du, X.H.; Wu, B.L. Improved Mechanical Properties of AZ31 Alloy Fabricated by Multi-Directional Forging Key Eng. Mater. 2017, 727, 124-131. [CrossRef]

31. Guo, Q.; Yan, H.; Chen, Z.; Zhang, H. Effect of mutiple forging process on microstructure and mechanical properties of Magnesium alloy AZ80. Acta Metall. Sin. 2006, 42, 739-744.

32. Jiang, M.G.; Yan, H.; Chen, R.S. Microstructure, texture and mechanical properties in an as-cast AZ61 Mg alloy during multidirectional impact forging and subsequent heat treatment. Mater. Des. 2015, 87, 891-900. [CrossRef]

33. Jiang, M.; Yan, H.; Chen, R. Enhanced mechanical properties due to grain refinement and texture modification in an AZ61 Mg alloy processed by small strain impact forging. Mater. Sci. Eng. A 2015, 621, 204-211. [CrossRef]

34. Hou, X.L.; Cao, Z.Y.; Wang, L.D.; Wang, L.M. Investigation on the Microstructure and Mechanical Properties of Hot Forged Mg-8Gd-2Y-1Nd-0.3Zn-0.6Zr Alloy. Adv. Mater. Res. 2011, 284-286, 1598-1602. [CrossRef]

35. Han, X.Z.; Xu, W.C.; Shan, D.B. Effect of precipitates on microstructures and properties of forged Mg-10Gd-2Y-0.5Zn-0.3Zr alloy during ageing process. J. Alloys Compd. 2011, 509, 8625-8631. [CrossRef]

36. Xia, X.; Chen, Q.; Zhao, Z.; Ma, M.; Li, X.; Zhang, K. Microstructure, texture and mechanical properties of coarse-grained $\mathrm{Mg}-\mathrm{Gd}-\mathrm{Y}-\mathrm{Nd}-\mathrm{Zr}$ alloy processed by multidirectional forging. J. Alloys Compd. 2015, 623, 62-68. [CrossRef]

37. Wu, D.; Li, S.Q.; Hong, M.; Chen, R.S.; Han, E.H.; Ke, W. High cycle fatigue behavior of the forged Mg-7Gd-5Y-1Nd-0.5Zr alloy. J. Magnes. Alloys 2014, 2, 357-362. [CrossRef]

38. Dong, B.; Zhang, Z.; Yu, J.; Che, X.; Meng, M.; Zhang, J. Microstructure, texture evolution and mechanical properties of multidirectional forged Mg-13Gd-4Y-2Zn-0.5Zr alloy under decreasing temperature. J. Alloys Compd. 2020, 823, 153776. [CrossRef]

39. Liu, B.; Zhang, Z.; Jin, L.; Gao, J.; Dong, J. Forgeability, microstructure and mechanical properties of a free-forged Mg-8Gd-3Y-0.4Zr alloy. Mater. Sci. Eng. A 2016, 650, 233-239. [CrossRef] 
40. Xin, R.; Song, B.; Zeng, K.; Huang, G.; Liu, Q. Effect of aging precipitation on mechanical anisotropy of an extruded Mg-Y-Nd alloy. Mater. Des. 2012, 34, 384-388. [CrossRef]

41. Wang, Z.Q.; Chen, J.; Wei, T.; Yan, W. Effect of Zr content on Grain size and Solution Treatment of Mg-5Gd-3Y-xZr alloy. J. Xian Technol. Univ. 2015, 35, 317-321.

42. Niknejad, S.; Esmaeili, S.; Zhou, N.Y. The role of double twinning on transgranular fracture in magnesium AZ61 in a localized stress field. Acta Mater. 2016, 102, 1-16. [CrossRef]

43. Cizek, P.; Barnett, M.R. Characteristics of the contraction twins formed close to the fracture surface in $\mathrm{Mg}-3 \mathrm{Al}-1 \mathrm{Zn}$ alloy de-formed in tension. Scr. Mater. 2008, 59, 959-962. [CrossRef]

44. Yu, H.; Xin, Y.; Chapuis, A.; Huang, X.; Xin, R.; Liu, Q. The different effects of twin boundary and grain boundary on reducing tension-compression yield asymmetry of Mg alloys. Sci. Rep. 2016, 6, 29283. [CrossRef] [PubMed]

45. Zhang, W.; Yu, Y.; Zhang, X.; Chen, W.; Wang, E. Mechanical anisotropy improvement in ultrafine-grained ZK61 magnesium alloy rods fabricated by cyclic extrusion and compression. Mater. Sci. Eng. A 2014, 600, 181-187. [CrossRef]

46. Mises, R.V. Mechanik der plastischen Formänderung von Kristallen. J. Appl. Math. Mech. 1928, 8, 161-185. [CrossRef] 